\title{
New Spectrofluorimetric Method for Determining Cadaverine Following Derivation with Orthophthalaldehyde: Application in Fish Tissue
}

\author{
Moumouny Traoré ${ }^{1}$, Khemesse Kital ${ }^{1}$, Moussa Mbaye ${ }^{1}$, Olivier Maurice Aly Mbaye ${ }^{1}$, Cheikh Diop ${ }^{1}$, Marina \\ Koussemon Camara ${ }^{2}$, Lamine Cissé ${ }^{1}$, Mame Diabou Gaye Seye ${ }^{1}$, Atanase Coly ${ }^{1}$, Alphonse Tine ${ }^{1}$ \\ ${ }^{1}$ Laboratoire de Photochimie et d'Analyse (LPA) - Faculté des Sciences et Techniques, Université Cheikh Anta DIOP, \\ Dakar, Sénégal. B.P. 5005 Dakar-Fann, Senegal \\ ${ }^{2}$ Laboratoire de Biotechnologie et Microbiologie des Aliments-UFR des Sciences et Technologies des Aliments, \\ Université Nangui Abrogoua, Cote d'Ivoire \\ Correspondence: Alphonse Tine, Laboratoire de Photochimie et d'Analyse (LPA) - Faculté des Sciences et Techniques, \\ Université Cheikh Anta DIOP, Dakar, Sénégal. B.P. 5005 Dakar-Fann, Senegal. E-mail: alphtine@yahoo.fr
}

Received: March 23, 2017 Accepted: May 11, $2017 \quad$ Online Published: May 14, 2017

doi:10.5539/ijc.v9n3p10 URL: https://doi.org/10.5539/ijc.v9n3p10

\begin{abstract}
A new spectrofluorimetric method was developed in this study for simple determination of cadaverine (CD) (1,5-diaminopentane) in flesh of mackerel fish. This method required homogenization of the flesh, solid phase extraction (SPE) with $0.4 \mathrm{M} \mathrm{HCl} / \mathrm{methanol}$ or water/methanol $(25 / 75 \mathrm{v} / \mathrm{v})$, centrifugation and derivation with orthophthalaldehyde (OPA). Physico-chemical parameters that affected the sensitivity of the fluorescence signal of the cadaverine-dihydrochloride/orthophthalaldehyde complex (CD/OPA), were optimised; these included reaction time, temperature, solvent system, $\mathrm{pH}$ and reactants concentrations (OPA/CD). The study was conducted in acetate buffer ( $\mathrm{pH} 3.5$ and 7) and showed low limits of detection (LOD), 0.6 and $25.5 \mathrm{ng}$. $\mathrm{mL}^{-1}$ respectively. The limits of quantification (LOQ) obtained were $3.5 \mathrm{ngmL}^{-1}$ (pH 3.5) and $122 \mathrm{ngmL}^{-1}$ (pH 7). The sensitivity of the results allowed its satisfactory application for quantification of cadaverine in fish.
\end{abstract}

Keywords: spectrofluorimetric method, cadaverine, mackerel fish, extraction, derivation, orthophthalaldehyde

\section{Introduction}

Biogenic amine refers to a group of biomolecules with different chemical structures and a common amine group which have a biological origin. Those molecules are synthetized by micro-organism on human, animal and plants tissus (Ladero, Calles-Enríquez, Fernández, \& Alvarez, 2010). This synthesis is done through the amino acid decarboxylation metabolic way. The mechanism of the reaction includes the elimination of the $\alpha$-carboxyl group from the amino acid. The amino acid decarboxylase needs pyridoxal-5-phosphate or pyruvoyl coenzymes to catalyze the reaction (Kamath, Vaaler, \& Snell, 1991). The product of this decarboxylation is an amine also called biogenic amine. However, only few classes of microorganisms are able to produce this biogenic amine according to their ability to synthetize specific carboxylase. This reaction has been said to optimally occur at pH ranging between 4.0 and 5.5 (Dapkevicius, Nout, Rombouts, Houben, \& Wymenga, 2000). In addition, specificity of the biogenic amines produced is correlated to the strains (ten Brink, Damink, Joosten, \& Huis in 't Veld, 1990). For example, enterobacteria are mainly producers of putrescine and cadaverine while enterococcis produce mostly Tyramine (ten Brink, Damink, Joosten, \& Huis in 't Veld, 1990., Suzzi, \& Gardini, 2003). These microorganisms are a part of the food flora or can be introduced by contamination before or during foodstuffs handling. Several factors like $\mathrm{pH}$, conservation, and temperature can influence the decarboxylation of amino acids (Santos, 1996). This is why most food that contains a high level of protein may have a large quantity of biogenic amines. So food substances that are prepared by the process of fermentation or exposed to microbial contamination during aging or conservation are likely to contain a large quantity of biogenic amines. As a result of this fact, the first stages of fermentation are crucial in the formation of biogenic amines (ten Brink, Damink, Joosten, \& Huis in 't Veld, 1990., Latorre-Moratalla, Bover-Cid, \& Vidal-Carou, 2010).

Biogenic amines are known as sources of nitrogen and precursors for the synthesis of hormones, alkaloids, nucleic acids and proteins (Bouchereau, Guénot, \& Larher, 2000., Jansen, van Dusseldorf, Botterma, \& Dubois, 2003). They can equally influence metabolic processes in an organism such as the regulation of body temperature, synapse transmission, allergic reaction, cellular division and proliferation of malignant cells, control of blood pressure, arterial pressure and cell growth (Bouchereau, Guénot, \& Larher, 2000, Halász, \& Baráth, 2002, Jansen, van Dusseldorf, Botterma, \& 
Dubois, 2003, Bashan, Holguin, \& Bashan, 2004., Önal, 2007). This is why the amount of biogenic amines in fish products has been reported in many studies (Heidi, \& Collin, 2005, Tine, \& Douabale, 2008, Simat, \& Dalgaard, 2011, Randy, \& Wen-Hsin, 2012). In fact, the level of free amino acids present in fish increases progressively as a function of the degree of fish freshness, temperature and time of conservation because of the proteolysis of endogens and exogenous enzymes (Makarios-Laham, \& Lee, 1993., Carelli, Centonze, Palermo, Quinto, \& Rotunno, 2007). By the way, in non-fermented foods, the presence of biogenic amines is indicative of undesirable microbial activity (Shakila, Vasundhara, \& Kumudavally, 2001., Anli, \& Bayram, 2009). As a result of their special odors cadaverine and putrescine can be used as indicators of food quality, particularly fish (Chytiri, Paleologos, Savvaidis, \& Kontominas, 2004., Ehsani, \& Jasour, 2012). In fact, we can observe an increasing levels of putrescine and cadaverine after the fish is dead, in the flesh of badly conserved fish, while the rate of spermine and spermidine goes down (Ruiz-Capillas, \& Fménez-Colmenero, 2004). Some biogenic amines are used as indicators of cancer in an organism due to the high amounts of cadaverine in blood and urine (prostate, diabetes, arthritis and fibrose), (Khuhawar, Memon, \& Bhanger, 2000, Awan, Fleet, \& Thomas, 2008).

Cadaverine $\left(\mathrm{NH}_{2}\left(\mathrm{CH}_{2}\right)_{5} \mathrm{NH}_{2}\right)$ known by the names 1,5-diaminopentane or pentamethylenediamine is a diamine (figure 1). It was isolated with putrescine in 1887 by Brieger (Brieger, 1887) as part of the Vibrio cholerae culture.

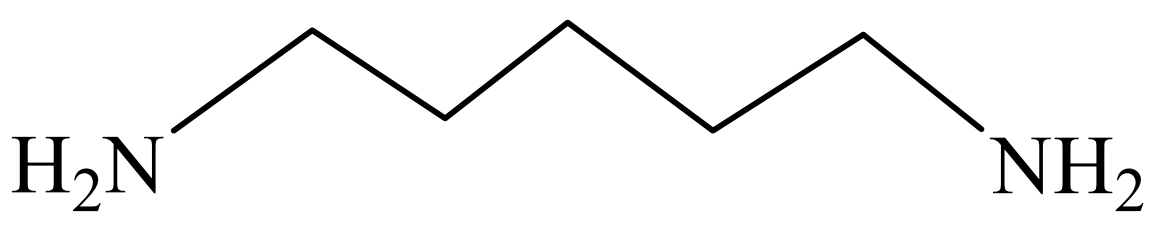

Figure 1. Structure of cadaverine

The stench of cadaverine comes from the hydrolysis of certain proteins during the putrefaction of dead bodies; hence his name (Antoine et al, 2004). It is mostly produced in foods by decarboxylation of lysine. This amine indicates the evaluation of the degree of microbial alteration of a very large number of fish as free lysine. It is present in many species of fish. The absence of cadaverine in a sample is therefore a reflection of the good quality of the fish (Li, Bao, Luo, Shen, \& Shi, 2012). In food, the major concern of consumers is the ability of cadaverine to potentiate the toxicity of other amines, specifically histamine (Lehane, \& Olley, 1999, Al Bulushi, Poole, Deeth, \& Dykes, 2009, EFSA, 2011). In addition, cadaverine can react with nitrite when heated to form the n-nitrosopiperidine, which is a carcinogenic nitrosamine (Al Bulushi, Poole, Deeth, \& Dykes, 2009); which constitutes an additional toxicological risk.

So it is important to monitor the amount of biogenic amines in foods particularly in fish products. The improvement of the sanitary quality of seafood has become a major preoccupation of governments and all stakeholders in this field.

Due to the increasing need for quality and hygiene of fish products, most countries had strengthened their regulation. This can explained why many analysis methods have been developed for the detection and quantification of biogenic animes in fish and fish products. These methods include, thin layer chromatography (Shalaby, 1995); high pressure liquid chromatography (Li et al., 2013., Önal, Tekkeli, \& Önal, 2013., de Figueiredo et al., 2015., Ibarra et al.,2015., Lee, Yoo, \& Shin, 2015), gas chromatography (Khuhawar, Memon, \& Bhanger, 2000), (Almeida, Fernandes, \& Cunha, 2012) and capillary zone electrophoresis (Arce et al., 1997). The revision of these chromatographic methods by Önal (Önal, Tekkeli, \& Önal, 2013) shows that they often require sophisticated equipment with trained staff. Thus, the greater parts of these apparatus are not readily available in developing country, for routine work. Therefore a new simple, easier, sensitive and available method is needed. In this regard this work aimed at developing a new spectrofluorimetric method to determine cadaverine levels in fish products.

\section{Experimental}

\subsection{Chemicals and Solvents}

All reagents used were of analytical grade. Cadaverine dihydrochloride (CD, 99\%, m/m), orthophthalaldehyde (OPA, $97 \%, \mathrm{~m} / \mathrm{m})$, methanol $(\mathrm{MeOH})$, sodium hydroxide $(\mathrm{NaOH}, 98 \%, \mathrm{~m} / \mathrm{m})$ and hydrochloric acid $(\mathrm{HCl}, 37 \%, \mathrm{~m} / \mathrm{m})$ were bought at Sigma-Aldrich (Taufkirchen, Germany). Trichloroacetic acid (TCA, $99 \%, \mathrm{~m} / \mathrm{m})$, sodium acetate $\left(\mathrm{CH}_{3} \mathrm{COONa}\right)$ and glacial acetic acid $\left(\mathrm{CH}_{3} \mathrm{COOH}\right)$ were purchased from Carlo Erba (France). Distilled water was used for regent preparation.

\subsection{Equipment}

For measurements, a spectrofluorimeter Perkin Elmer LS-55 model connected to a microcomputer and driven by the FL WinLab software was used. A parallelepiped quartz cuvette $(1 \mathrm{~cm}$ optical path, inside volume $3.5 \mathrm{ml})$ with five smooth 
surfaces was used for the analytical measurements. For the centrifugation, it was used a Bioblock Scientific, Dusseldorf, Germany apparatus. Weighing was carried out using a precision balance of accuracy $0.1 \mathrm{mg}$ from Sartorius AG Gottingen (Type BA 110S-OF1). The dilutions were performed using brand micropipettes Gilson, France. A pH meter from HANNA Instruments was also used.

\subsection{Preparation of Solutions}

Stock solutions of cadaverine $\left(1 \times 10^{-2} \mathrm{M}\right)$ and OPA $\left(1 \times 10^{-2} \mathrm{M}\right)$ were prepared; OPA required a little methanol to facilitate dissolution $(1 / 10, \mathrm{v} / \mathrm{v})$. Working solutions were obtained by diluting the stock solutions in the appropriate solvent.

All solutions were protected from light with aluminium foil and stored in a refrigerator at $278 \mathrm{~K}$. The stock solutions of $\mathrm{HCl}(1 \mathrm{M})$ and $\mathrm{NaOH}(1 \mathrm{M})$ were prepared with distilled water and used with or without dilutions according to the case.

\subsubsection{Samples Preparation}

Extractions were performed as previously described by Richard (Richard, Pivarnik, Ellis, \& Lee, 2011) and AOAC (AOAC, 1995). 25g of fish meat were removed (avoiding as much as possible the bones and the scales). The flesh removed was ground and $10 \mathrm{~g}$ of the ground tissue are introduced into $65 \mathrm{~mL}$ of a mixture of $\mathrm{HCl} / \mathrm{methanol}(25 / 75, \mathrm{v} / \mathrm{v})$ or water/methanol $(25 / 75, \mathrm{v} / \mathrm{v})$. The resulting mixture was centrifuged at $1073 \mathrm{~g}$ for 5 minutes. The supernatant (containing extract) was collected and heated in a water bath at $333 \mathrm{~K}$ for 15 minutes to eliminate methanol. After cooling at room temperature, it was filtered using a whatman filter paper. The resulting extract was kept in the refrigerator at $278 \mathrm{~K}$ until analysis.

\subsubsection{Method for Standard Addition}

For a quantitative analysis of an analyte in a matrix, one often uses the method of standard addition to evaluate the degree of interference caused by the presence of other substances. It consists in adding a constant volume of unknown sample to standard solutions of increasing concentrations, the first addition being done in the blank. The linear increase allows the deduction of the concentration of the unknown sample by way of interpolation.

\subsection{Data Analysis}

All data were treated using MicroCal software, Origin Lab, Northampton and MA software version 8.5.

\section{Results and Discussions}

\subsection{Preliminary Study}

First, we proposed to study the stoichiometry of the reaction of complexation between cadaverine and orthophthalaldehyde (OPA) because cadaverine and OPA are non-fluorescent substances in water. To do this, concentrations of cadaverine ranging from $2 \times 10^{-5} \mathrm{M}$ to $2 \times 10^{-4} \mathrm{M}$ were added to a fixed concentration of OPA ( $4 \times 10^{-}$ ${ }^{4} \mathrm{M}$ ) and fluorescence signal was measured for each concentration of cadaverine. The concentrations of OPA and cadaverine corresponding to the maximum fluorescence intensity allowed to determine the stoichiometry of the complex. Indeed, the fluorescence intensity of the complex OPA/CD is maximal when the reaction mixture contains an OPA concentration double that of cadaverine. We can pretend that each OPA molecule reacts with a group of amine where the stoichiometry is $2: 1$ in water.

The excitation and emission spectra (Figure 2) were recorded after complexation of both substances. The shape of spectra structure is the same in all solvents studied (two peaks of excitation and one peak of emission). In water, the excitation spectrum has two peaks localized at $234 \mathrm{~nm}$ and $281 \mathrm{~nm}$ respectively, while the emission spectrum was located at $313 \mathrm{~nm}$ (Figure 2). 


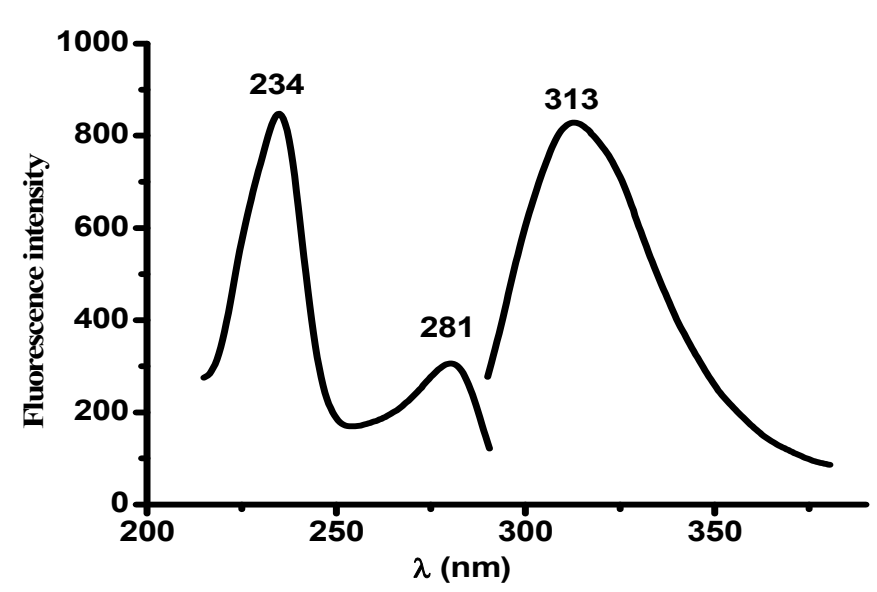

Figure 2. Fluorescence excitation and emission spectra of OPA/CD complex $2 \times 10^{-4} \mathrm{M}$ in water at $298 \mathrm{~K}$

\subsection{Optimization of Analytical Parameters}

\subsubsection{Effect of $\mathrm{pH}$ in an Aqueous Medium}

Studies reveal that the fluorescence signal of organic compounds is very sensitive in $\mathrm{pH}$ changes of the medium (Coly, \& Aaron, 2009). The protonation or deprotonation of functional groups modifies profoundly many fluorophores in their excitation and emission spectra (Coly, \& Aaron, 2009). This is why we planned to study the effect of $\mathrm{pH}$ on the fluorescence of OPA/CD complex. Figure 3 shows that the fluorescence intensity increases gradually between the values 1 and 3.5, while it slowly decreases between the values 3.5 and 9. The spectra of the complex OPA/CD formed in an acid medium have the same form as those obtained in basic medium. The curve shows a maximum at $\mathrm{pH}$ 3.5. From $\mathrm{pH}$ values higher than 9, the fluorescence intensity drops sharply as the $\mathrm{pH}$ increases. This indicates that in the basic medium, the complex OPA/CD is hardly detectable by fluorescence method. This significant decrease in fluorescence intensity is probably due to the dissociation of the complex. This observation leads us to the selection of the acid medium for the next stage of the study.

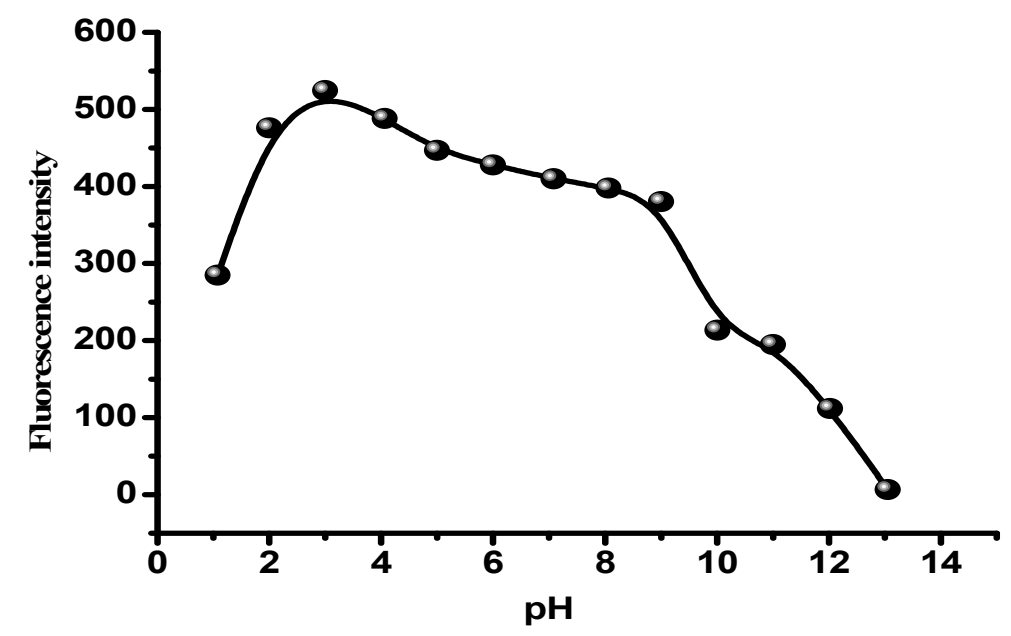

Figure 3. $\mathrm{pH}$ effect on the fluorescence intensity of OPA/CD complex $2 \times 10^{-4} \mathrm{M}$ in water at $298 \mathrm{~K}\left(\lambda_{\mathrm{ex}}=234 \mathrm{~nm} ; \lambda_{\mathrm{em}}=\right.$ $313 \mathrm{~nm})$

\subsubsection{Kinetics of the OPA/CD Complex Formation}

In order to improve the chosen fluorescence method, the stability of the complex formed was studied. We studied the complex for 5 minutes in water at optimal $\mathrm{pH}$ (3.5). After mixing the two reagents, the kinetic study started by monitoring the fluorescence signal over time. We noticed that the resulting complex was relatively stable in water (Figure 4). 


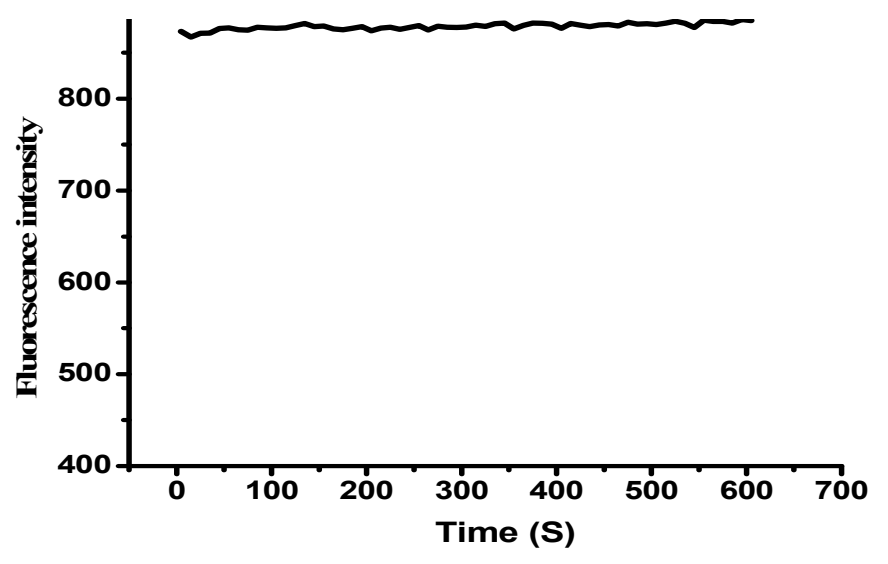

Figure 4. Evolution of the fluorescence intensity of OPA/CD complex $2 \times 10^{-4} \mathrm{M}$ in water at $298 \mathrm{~K}$

\subsubsection{Effect of Temperature on the OPA/CD Complex}

Previous studies indicated that temperature has a remarkable effect on the kinetics of the complex OPA /histamine. So, it was deemed necessary to study the effect of heat on the fluorescence intensity of the complex OPA/CD. It was observed that, there was a decrease in the fluorescence intensity of the complex in correlation with the increase in temperature, (Figure 5). This increase in temperature causes the dissociation of the complex, which causes a reduction of the fluorescence intensity. This observation is in agreement with that reported in the literature (Khonté et al., 2015) . This process is reversible, because by cooling the solution, we observed an increase in fluorescence intensity due to the reconstitution of the complex. However, above a certain temperature (303K), it was observed that the decrease in the fluorescence signal was relatively slow.

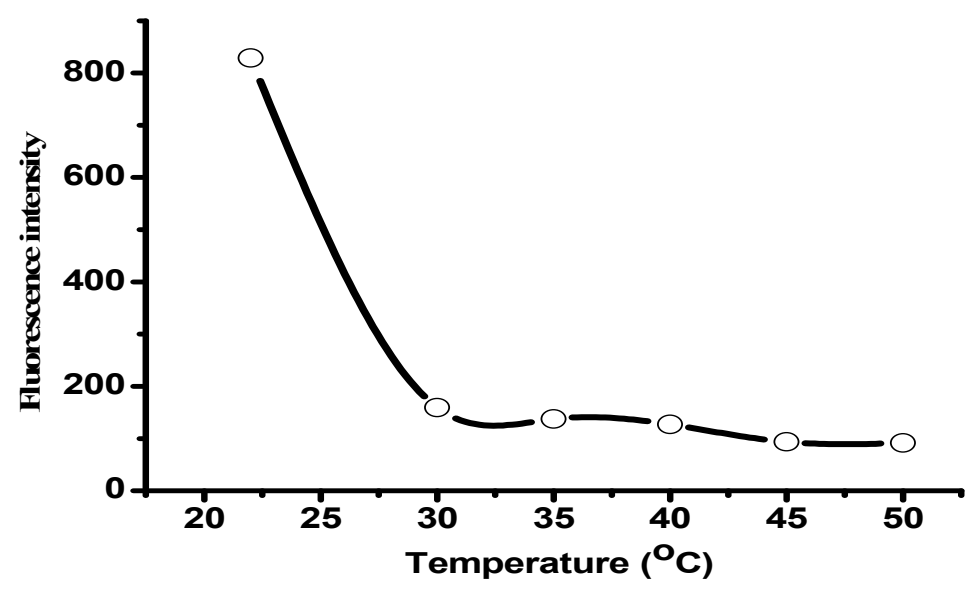

Figure 5. Effect of temperature on fluorescence intensity of OPA/CD complex $\left(2 \times 10^{-4} \mathrm{M}\right)$ in aqueous media

\subsubsection{Effect of Binary Buffered Media (Water/MeOH) at $\mathrm{pH} 3.5$ and 7}

To predict the influence of methanol levels in water $/ \mathrm{MeOH}$ mixture given the optimum analytical conditions of cadaverine, we varied the proportions of $\mathrm{MeOH}$ in different water/MeOH mixtures (Figure 6). We recorded the fluorescence spectrum of each buffer water/ $\mathrm{MeOH}$ mixture at $\mathrm{pH} 3.5$ and 7. In buffer solution $\mathrm{pH} 3.5$, the fluorescence signal is highest for the water/MeOH mixture $(95: 5, \mathrm{v} / \mathrm{v})$, while at neutral $\mathrm{pH}$, methanol progressively inhibits the fluorescence signal. The progressive decrease in the fluorescence intensity with the addition of large amounts of $\mathrm{MeOH}$ could be due to the phenomenon of salvation (Khonté et al., 2015) . In addition, the continuous addition of methanol in the reaction medium increases the dissociation of OPA/CD complex where there is a decrease in the observed fluorescence intensity. After extraction of the cadaverine from the sample with the binary mixture water $/ \mathrm{MeOH}$, to avoid (the) inhibition of the signal, it would be wise to heat in order to drive off the traces of methanol. 

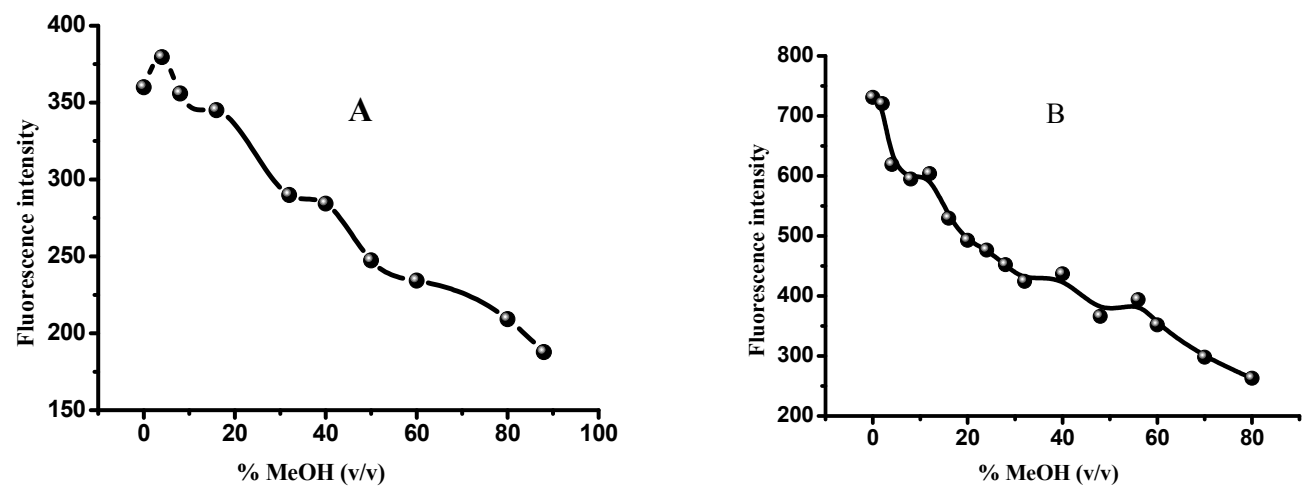

Figure 6. Variation effect of $\mathrm{MeOH}$ on the fluorescence signal of $\mathrm{OPA} / \mathrm{CD}$ complex $\left(2 \times 10^{-4} \mathrm{M}\right)$ at $298 \mathrm{~K}, \mathrm{pH}=7$ (A) and $\mathrm{pH} 3.5$ (B). $\left(\lambda_{\mathrm{ex}}=234 \mathrm{~nm} ; \lambda_{\mathrm{em}}=313 \mathrm{~nm}\right)$

\subsection{Analytical Performance}

To evaluate the analytical effectiveness of our proposed method, we established a calibration curve of cadaverine in water at $\mathrm{pH} 3.5$; and $\mathrm{pH} 7$; comparing the two experimental results. We chosed this medium ( $\mathrm{pH} 7$ and 3.5) because it showed a very large intensity of emission of the complex (OPA/CD). We obtained a linear correlation between the fluorescence intensity and the concentration of the CD (Table 1) with a correlation coefficient ranging from 0.996 to 0.997, this indicated the precision of our measurements. Using the calibration curves, we determined some analytical parameters (Table 1).Ten measurements were used to achieve the results of the Table 1. The study of analytical performance of the method led to the detection limits (LOD) of $0.6 ; 25.5 \mathrm{ngmL}^{-1}$ and quantification limits (LOQ) of 3.5; $122 \mathrm{ngmL}^{-1}$, respectively at $\mathrm{pH} 3.5$ and $\mathrm{pH}$ 7. The values of the relative standard deviation (RSD) are relatively low, these are evidence of good precision and reproducibility of our measurements. Statistical data indicated that better results were obtained in acetate buffer $\mathrm{pH}$ 3.5. Indeed, the acetate buffer presented many advantages, both in terms of stability and sensitivity of the complex OPA/CD.

Table 1. Spectrofluorimetric analytical figures of merit for the determination of $\mathrm{CD}$ in buffer $(\mathrm{pH}=3.5$ and $\mathrm{pH}=7)$

\begin{tabular}{llllll}
\hline Medium & $\begin{array}{l}\mathrm{LDR}^{\mathrm{a}} \\
\left(\mathrm{ngmL}^{-1}\right)\end{array}$ & $\begin{array}{l}\mathrm{LOD}^{\mathrm{b}} \\
\left.(\mathrm{ngmL})^{-1}\right)\end{array}$ & $\begin{array}{l}\mathrm{LOQ}^{\mathrm{c}} \\
\left(\mathrm{ngmL}^{-1}\right)\end{array}$ & $\begin{array}{c}\mathrm{RSD}^{\mathrm{d}} \\
\left(\mathrm{ngmL}^{-1}\right)\end{array}$ & $\begin{array}{c}\mathrm{r}^{2 \mathrm{e}} \\
\text { Water }(\mathrm{pH}=3,5)\end{array}$ \\
Water $(\mathrm{pH}=7)$ & $4-697$ & 0.6 & 3.5 & 2 & 0,997 \\
\hline
\end{tabular}

${ }^{a}$ Linear dynamic range, ${ }^{b}$ Limit of detection, defined as the amount of analyte giving a signal-to-noise ratio of $3,{ }^{c}$ Limit of quantification, defined as the amount of analyte giving a signal-to-noise ratio of 10 , ${ }^{\mathrm{d}}$ Mid-range relative standard deviation $(\mathrm{n}=6-8),{ }^{\mathrm{e}}$ Correlation coefficients.

\subsection{Analytical Application}

To verify the presence of cadaverine in our fish sample, extraction was performed according to Richard and the AOAC methods (AOAC, 1995, Richard, Pivarnik, Ellis, \& Lee, 2011), as previously described. Figure 7 shows that the excitation and emission spectra of the complex and the extract are perfectly superimposable, confirming the presence of cadaverine in the mackerel sample. The solvent $0.4 \mathrm{M} \mathrm{HCl} / \mathrm{methanol}(25 / 75, \mathrm{v} / \mathrm{v})$ gave a greater fluorescence intensity of the complex OPA/CD. This results showed that this solvent was better and more selective for cadaverine extraction in fish samples. Indeed, some researchers reported that the solvent of extraction $0.4 \mathrm{M} \mathrm{HCl} / \mathrm{methanol}(25 / 75, \mathrm{v} / \mathrm{v})$ allows for more recovery of cadaverine and putrescine in the flesh of fish. This, regardless of the fat content, the handling conditions and the size of the fish sample (Richard, Pivarnik, Ellis, \& Lee, 2011). 


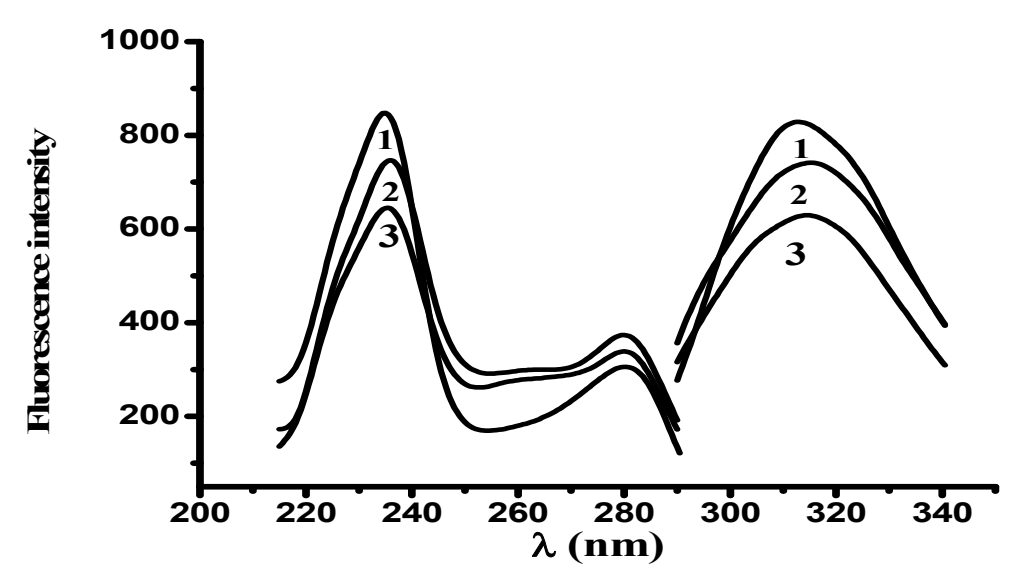

Figure 7. Fluorescence excitation and emission of OPA/CAD complex: Standard solution (1); after extraction in $\mathrm{MeOH} / \mathrm{HCl}$ mixture (2) and $\mathrm{MeOH} /$ water mixture (5:95, v/v) (3)

Furthermore, for a better quantitative analysis of cadaverine in the sample, we prepared an additional curve to evaluate the degree of interference of other substances present in the matrix (Diaw et al., 2014, Khonté et al., 2015),. The slopes of the calibration curves and standard addition are very close (Figure 8). This parallelism of the two curves indicated lower sensitivity to interfering substances and negligible matrix effect (Khonté et al., 2015).

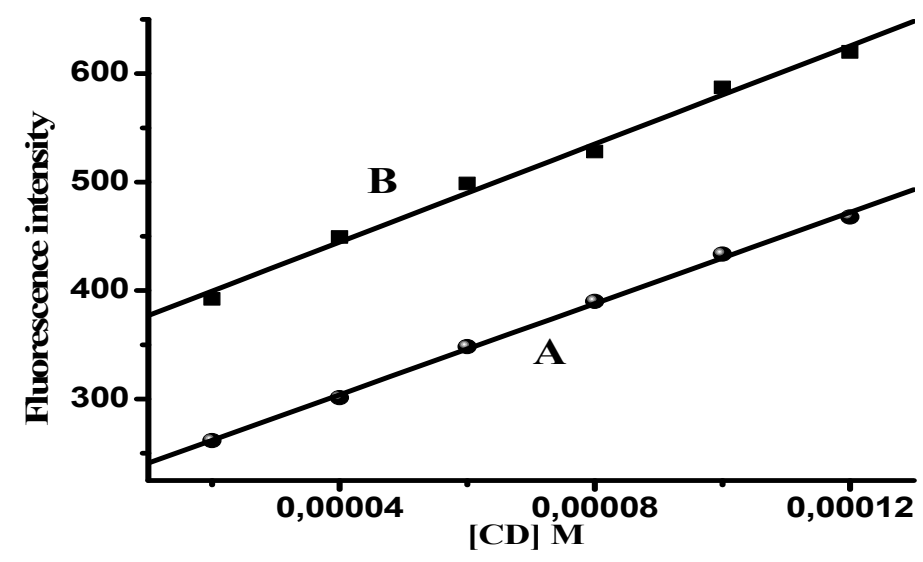

Figure 8. Straight calibration curve: Calibration curve of CD in water (A); Standard addition curve of the sample in fish (B) $\left(\lambda_{\text {ex }}=234 \mathrm{~nm}, \lambda_{\mathrm{em}}=313 \mathrm{~nm}\right)$.

This was confirmed by the satisfactory percentage recovery between 82.4 and 97.7 (Table 2).

The recovery rate $(\% \mathrm{R})$ was determined according to the following relationship below.

$$
\% \mathrm{R}=\frac{\mathrm{Ct}}{\mathrm{Ca}+\mathrm{C} 0} \times 100
$$

This rate allowed to evaluate the interference effects for each concentration in the linearity domain of the calibration curve. Thus, to the extent of its applicability, in agreement with the validation of analytical methods, this rate must be between 80 and $120 \%$.

Ct: concentration of CAD found, Ca: concentration added; C0: Blank concentration (13.5ng.mL $\left.\mathrm{mL}^{-1}\right)$.

The average percentage recovery was very good (93\%) which was not far from $100 \%$. The relative standard deviation was low $(5.19 \%)$ attesting to the good precision of our measurements (Table 2). These values were consistent with international standards for the validation of the analytical method (Khonté et al., 2015). Researchers have obtained a recovery percentage of $97 \%$ for mackerel (Richard, Pivarnik, Ellis, \& Lee, 2011). 
Table 2. Evaluation of recovery values in mackerel by solid-phase extraction procedure (SPE)

\begin{tabular}{cccc}
\hline $\begin{array}{c}\text { Added }(\mathrm{Ca}) \\
\left(\mathrm{ng} \cdot \mathrm{mL}^{-1}\right)\end{array}$ & $\begin{array}{c}\text { Found }(\mathrm{Ct}) \\
\left(\text { ng. } \mathrm{mL}^{-1}\right)\end{array}$ & Recovery $(\% \mathrm{R})$ & Mean Recovery (\%) \\
\hline 0 & 13.5 & - & \\
3.5 & 14.0 & 82.4 & \\
7.0 & 19.1 & 93.2 & $93,0 \pm 5.19$ \\
10.5 & 23.5 & 980 & \\
14.0 & 25.4 & 92.4 & \\
17.5 & 30.3 & 97.7 & \\
21.0 & 32.6 & 94.5 & \\
\hline
\end{tabular}

\section{Conclusion}

In this work, a simple, sensitive, accurate and inexpensive method for the determination of cadaverine in fish sample (mackerel) was developed. We demonstrated the usefulness of the spectrofluorometric method of analysis with the optimization of different parameters which could affect the fluorescence intensity of the complex OPA/CAD in water. The analytical performances confirmed the good sensitivity and precision of our method. We also showed the applicability of the method for the determination of cadaverine in fish samples in the range of $\mathrm{ng} / \mathrm{mL}$ with good recovery percentage values and low interference effects. Therefore, our method can be proposed for routine analysis. We intend to apply this method to other biological matrices other than fish.

\section{Acknowledgments}

This work was financed partly by a scholarship UE-ACP (PIMASO).

\section{References}

Al Bulushi, I., Poole, S., Deeth, H. C., \& Dykes, G. A. (2009). A Review Critical Reviews in Food Science and Nutrition, 49(4), 369-377.

Almeida, C., Fernandes, J. O., \& Cunha, S. C. (2012). Food Control, 25, 380-388. https://doi.org/10.1016/j.foodcont.2011.10.052

Anli, R. E., \& Bayram, M. (2009). Food Rev. Int., 25, 86-102. https://doi.org/10.1080/87559120802458552

Antoine, F. R., Wei, C. I., Otwell, W. S., Sims, C. A., Littell, R. C., Hogle, A. D., \& Marshall, M. R. (2004). J. Food Prot., 67, 2255-2262. https://doi.org/10.4315/0362-028X-67.10.2255

AOAC (1995). Official Methods of Analysis of the AOAC international, 16 ${ }^{\text {th }}$ ed. Method 970.12. Association of Official Analytical Chemists International. Washington, DC, USA

Arce, L., Rios, A., \& Valcarcel, M. (1997). Chromatographia, 46(3), 4170-4176.

Awan, M. A., Fleet, I., \& Thomas, C. L. P. (2008). Food Chemistry, 111(2), 462-468. https://doi.org/10.1016/j.foodchem.2008.03.068

Bashan, Y., Holguin, G., \& Bashan, L. E. (2004). Can. J. Microbiol, 50, 521-577. https://doi.org/10.1139/w04-035

Bouchereau, A., Guénot, P., \& Larher, F. (2000). J. Chromatogr. B. Biomed Sci. Appl., 747(1-2), 49-67. https://doi.org/10.1016/S0378-4347(00)00286-3

Brieger, L. (1887). Translated by, Roussy, J. Winter. Publisher, Doin, 1887. Original from, the University of California. Digitized, Jan 24, 2007. Length, 235 pages.

Carelli, D., Centonze, D., Palermo, C., Quinto, M., \& Rotunno, T. (2007). Biosensors and Bioelectronics, 23(5), 640647. https://doi.org/10.1016/j.bios.2007.07.008

Chytiri, S., Paleologos, E., Savvaidis, I., \& Kontominas, M. G. (2004). J. Food Prot., 67, 960-965. https://doi.org/10.4315/0362-028X-67.5.960

Coly, A., \& Aaron, J. J. (2009). Maced. J. Chem. Chem. Eng., 27, 33-40.

Dapkevicius, M. L. N. E., Nout, M. J. R., Rombouts, F. M., Houben, J. H., \& Wymenga, W. (2000). International Journal of Food Microbiology, 57, 107-114. https://doi.org/10.1016/S0168-1605(00)00238-5

De Figueiredo, T. C., de Assis, D. C., Menezes, L. D., da Silva, G. R., Lanza, I. P., Heneine, L. G., \& Cançado Sde, V. (2015). Talanta, 142(1), 240-245. https://doi.org/10.1016/j.talanta.2015.04.056

Diaw, P. A., Mbaye, O. M. A., Gaye-Seye, M. D., Aaron, J. J., Coly, A., Tine, A., ... Oturan, N. (2014). J. Fluoresc, 24, 1319-1330. https://doi.org/10.1007/s10895-014-1418-8 
EFSA Panel on Biological Hazards (BIOHAZ). (2011). Scientific Opinion on risk based control of biogenic amine formation in fermented foods. EFSA Journal, 9(10), 2393. https://doi.org/10.2903/j.efsa.2011.2393

Ehsani, A., \& Jasour, M. S. (2012). Journal of Food Science and Technology, 77(12), 664-668.

Halász, A., \& Baráth, Á. (2002). Food Science and technology, COST 917 Biogenically active amines in food volume VII.6, 131-41EC Publication, Luxembourg

Heidi, S. M., \& Collin, R. A. (2005). Journal of Chromatography A., 1094(1-2), 60-69. https://doi.org/10.1016/j.chroma.2005.07.088

Ibarra, A. A., Wrobel, K., Escobosa, A. R., Elguera, J. C., Garay-Sevilla, M. E., \& Wrobel, K. (2015). J. Chromatogr B Analyt. Technol. Biomed Life Sci., 1002, 176-184. https://doi.org/10.1016/j.jchromb.2015.08.036

Jansen, S. C., van Dusseldorf, M., Botterma, K. C., \& Dubois, A. E. (2003). A review. Ann. Allergy Asthma Immunol, 91(3), 233-240. https://doi.org/10.1016/S1081-1206(10)63523-5

Kamath, A. V., Vaaler, B. L., \& Snell, E. E. (1991). The Journal of Biological Chemistry, 266, 9432-9437.

Khonté, A., Thiaré, D. D., Diop, C., Cissé, L., Delattre, F., Coly, A., ... Gaye-Seye, M. D. (2015). International Journal of Chemistry, 7, 85-98. https://doi.org/10.5539/ijc.v7n2p85

Khuhawar, M. Y., Memon, A. A., \& Bhanger, M. I. (2000). Jour. Chem. Soc. Pak., 22(2), 267-270.

Ladero, V., Calles-Enríquez, M., Fernández, M., \& Alvarez, M. A. (2010). Current Nutrition Food Sci,.6, 145-156. https://doi.org/10.2174/157340110791233256

Latorre-Moratalla, M. L., Bover-Cid, S., \& Vidal-Carou, M.C. (2010). Meat Science, 85(3), 537-541. https://doi.org/10.1016/j.meatsci.2010.03.002

Lee, S., Yoo, M., \& Shin, D. (2015). LWT-Food Science and Technology, 62(1), 350-356. https://doi.org/10.1016/j.lwt.2015.01.016

Lehane, L., \& Olley, J. (1999). National Office of Animal and Plant Health,AustraliaCanberra.

Li, K., Bao, Y., Luo, Y., Shen, H., \& Shi, C. (2012). Journal of Food Protection, 75, 2228-2233. https://doi.org/10.4315/0362-028X.JFP-12-143

Li, Y., Yang, H., Liao, H., Fan, H., Liang, C., Deng, L., \& Jin, S. (2013). Journal of Chromatography B, Analytical Technologies in the Biomedical and Life Sciences, 929, 33-39. https://doi.org/10.1016/j.jchromb.2013.03.025

Makarios-Laham, I. K., \& Lee, T. C. (1993). Journal of Food Science and Technology, 58(2), 310-313.

Önal, A. (2007) Food Chem., 103, 1475-1486. https://doi.org/10.1016/j.foodchem.2006.08.028

Önal, A., Tekkeli, S. E., \& Önal, C. (2013). Food Chemistry, 138(1), 509-515. https://doi.org/10.1016/j.foodchem.2012.10.056

Randy, L. S, \& Wen-Hsin, W. (2012). Journal of Food Composition and Analysis, 27(2), 169-173. https://doi.org/10.1016/j.jfca.2012.06.002

Richard, N. L., Pivarnik, L. F., Ellis, P. C., \& Lee, M. C. (2011). Journal of AOAC International, 94(4).

Ruiz-Capillas, C., \& Fménez-Colmenero, J. (2004). Critical Rev. Food Sci. Nutrition, 44(7-8), 489-499. https://doi.org/10.1080/10408690490489341

Santos, M. H. (1996). International Journal of Food Microbiology, 29(2-3), 213-231. https://doi.org/10.1016/0168-1605(95)00032-1

Shakila, R. J., Vasundhara, T. S., \& Kumudavally, K. V. (2001). Food Chemistry, 75(2), 255-259. https://doi.org/10.1016/S0308-8146(01)00173-X

Shalaby, A. R. (1995). Food Chemistry, 52(4), 367-372. https://doi.org/10.1016/0308-8146(95)93283-W

Simat, V., \& Dalgaard, P. (2011). Food Science and Technology, 44, 399-406.

Suzzi, G., \& Gardini, F. (2003). Int. J. Food Microbiol, 88(1), 41-54. https://doi.org/10.1016/S0168-1605(03)00080-1

ten Brink, B. T., Damink, C., Joosten, H. M. L. J., \& Huis in 't Veld, J. H. J. (1990). International Journal of Food Microbiology, 11, 73-84. https://doi.org/10.1016/0168-1605(90)90040-C

Tine, A., \& Douabale, E. S. (2008). Reviews in Fluorescence, 195-218.

\section{Copyrights}

Copyright for this article is retained by the author(s), with first publication rights granted to the journal.

This is an open-access article distributed under the terms and conditions of the Creative Commons Attribution license (http://creativecommons.org/licenses/by/4.0/). 